\title{
Celiac Artery Compression by the Median Ligament: An Uncommon Cause of Abdominal Pain in the Emergency Department. Report of a Case
}

\author{
Enrico Ferri* ${ }^{*}$, Laura Magrini $^{1}$, Carlo Capotondi ${ }^{2}$, Marco Alfano ${ }^{1}$, Michela Del Parco ${ }^{1}$ and \\ Salvatore Di Somma ${ }^{1}$
}

\author{
${ }^{I}$ Department of Emergency Medicine, A.O. Sant'Andrea, La Sapienza University of Rome, Rome, Italy \\ ${ }^{2}$ Department of Radiology, Emergency Radiology Unit , A.O. Sant'Andrea, La Sapienza University of Rome, Rome, Italy
}

\begin{abstract}
The Authors report a case of a patient presenting in the Emergency Department (ED) with severe epigastric pain refractory to therapeutic treatment, with onset after forced ice water ingestion caused by joking compression of a soft PET $^{\circledR}$ bottle during drinking.

The Angio MR and angiography performed, after exclusion of suspected esophagus rupture and other esophago-gastric diseases, to rule out an ischemic origin of the pain demonstrate a stenosis of the celiac artery resulting from median arcuate ligament narrowing, the so-called Dunbar's Syndrome.

The Dunbar's Syndrome is uncommon and some aspects such as the vascular etiology of symptoms are still controversial.

In this report clinical presentation, differential diagnosis and pathophysiology of this disease are discussed.
\end{abstract}

Keywords: Celiac artery stenosis, Dunbar's syndrome, Median arcuate ligament syndrome, Abdominal pain, Emergency Department.

\section{INTRODUCTION}

Celiac artery compression also known as median arcuate ligament or Dunbar's syndrome is an uncommon disorder characterized, in symptomatic patients, by transient postprandial or exercise-related or chronic epigastric pain, hyperemesis, vomiting, diarrhoea and weight loss [1-6].

It may be considered also in asymptomatic patients presenting abdominal bruit or with palpated thrill in the upper epigastrium at physical examination $[2,3,5,7]$.

The incidence of median arcuate ligament is not clearly established, the majority of literature consisting of isolated reports $[1-4,8]$.

Either ischemic or neurogenic etiology have been proposed to explain the abdominal pain. However, based on observation of celiac artery compression in asymptomatic patients, questions have emerged as to whether celiac artery compression syndrome really exists $[1,7,9]$.

We report a case of Dunbar's syndrome in a young boy visited in an Emergency Department (ED) after forced ice water ingestion. Our case report seems to confirm the vascular ischemic etiology of the Dunbar's syndrome which has to be considered for the differential diagnosis of epigastric pain in the ED.

*Address correspondence to this author at the Department of Emergency Medicine, A.O. Sant'Andrea, La Sapienza University of Rome, Via di Grottarossa, 1035-1039, Rome, Italy; Tel: +3906337747111/5754/6758; Fax: +390633775018/5053;

E-mails: ferri.enrico@libero.it, eferri@ospedalesantandrea.it

\section{CASE REPORT}

A 16 years old boy was referred to our ED for evaluation of recent onset abdominal pain beginning after about 30 minutes after forced ice water ingestion caused by joking compression of a soft PET $^{\circledR}$ bottle during drinking. Additional symptoms included nausea, and vomiting. He did not drink alcohol or smoke and no risk factors for Hiv were present. There was not previous anamnestic relevant medical history or surgery.

Phisical general exam was normal in contrast with the severe epigastric pain. Rectal examination was unremarkable. Patient's timpanic temperature, heart rate and blood pressure were normal. Other workup including electrocardiographic examination, laboratory investigations including haemogram, c reactive protein, amylase, and lipase, abdominal and chest $\mathrm{x}$ ray and abdominal ultrasound were normal. Pain was unresponsive to protonic pump inhibitors or analgesic non steroidal inflammatory drugs medication (NSAIDs).

Correlation with pain onset and forced ice water ingestion suggested to the emergency physician a suspect of traumatic esophagus rupture, like Boerhaave syndrome, and to detect a pneumomediastinum and parietal esophageal abnormality a toraco-abdominal CT scan, an esophagogram and esophago-endoscopy were performed. But they did not show any abnormality.

Patient showed a spontaneous pain relief and was admitted to hospital stay in the Observation Unit where after 24 hours experienced post prandial epigastric pain and diarrhoea. An angio-MR of the abdomen was requested to rule out ischemic origin of pain correlated to an aortic dissection. 
Angio MR (Fig. 1) pointed out a celiac trunk stenosis (Dunbar's syndrome) confirmed by angiography. Patient was referred to vascular surgeon for surgical treatment.

\section{DISCUSSION}

The median arcuate ligament is formed by muscolar fibers that bridge the right and left crura of the diaphragm just anterior to the aorta at T 12-L1 level and it defines the anterior margin of the aortic hiatus [10]. The ligament is highly variable, with appearances ranging from a well defined ligamentous mass to an amorphous area of connective tissue. Supplementary fibers to the celiac plexus normally form a thick, resistant shield immediately ventral to the median arcuate ligament and may contribute to compression of the celiac artery $[11,12]$.

Compression of the celiac axis by extraluminal structures was first described in 1917 by the anatomist Lipshutz [13] but the association with a clinical syndrome was initially decribed by Harjola [14] in 1963, and by Dunbar [15] et al. in 1965 and it is a well documented anatomic variant, reportedly seen in $12.5 \%-49.7 \%$ of patients $[16,17]$.

The median arcuate ligament or Dunbar's syndrome has been documented in monozygotic twins, which suggests that the anatomical relationships, responsible for the disease, are congenital [18].

The stenosis of the celiac trunk occurs either in a too cranial emergence of the celiac artery from the aorta, or in a too caudal insertion of the left crux of the diaphragm on the lumbar vertebral column [7]. Results of conventional angiographic studies dating to the early 1970s showed that the position of the median arcuate ligament, celiac artery, and aorta varies considerably during respiration and that median arcuate ligament compression is often accentuated during expiration $[19,20]$.

In patients affected by median arcuate ligament syndrome, celiac artery compression occurs during expiration and is more evident with the patient in the erect position [8].

At expiration, infact, the aorta and its major branches, including the celiac artery move cephalad and this causes worsening of compression, while with inspiration the celiac artery descends lower in the abdominal cavity resulting in a more vertical orientation, which often relieves compression. Additional findings include poststenotic dilatation of the distal celiac trunk, dilated peripancreatic collateral vessels, pancreaticoduodenal artery aneurisms, atheromatous plaques in the aorta [21-23] and mitral valve prolapse [24].

Most of patients are young [1-4,8], thin individuals with acute post prandial (beginning from 15 to 30 minutes after meals), exercise related [1] or chronic epigastric pain, hyperemesis, vomiting, diarrhoea and weight loss [1-6].

Clinical manifestations are vague and diagnosis may rely on findings at duplex and color flow Doppler sonography $[2,8]$, angiographic $[2,3,19,20,21,25]$, CT $[3,4,9,21]$ or MR $[2,6,22]$ imaging but differentiation between clinically relevant celiac artery compression and incidental narrowing may be difficult [16,22].

Physical examination may reveal, classically, a bruit that varies with respiration and position [7] in the midepigastric region or a palpated thrill in the upper epigastrium [2,3,5,7].

The pathophysiologic origin of these symptoms is not clearly understood but the most accepted hypothesis is that

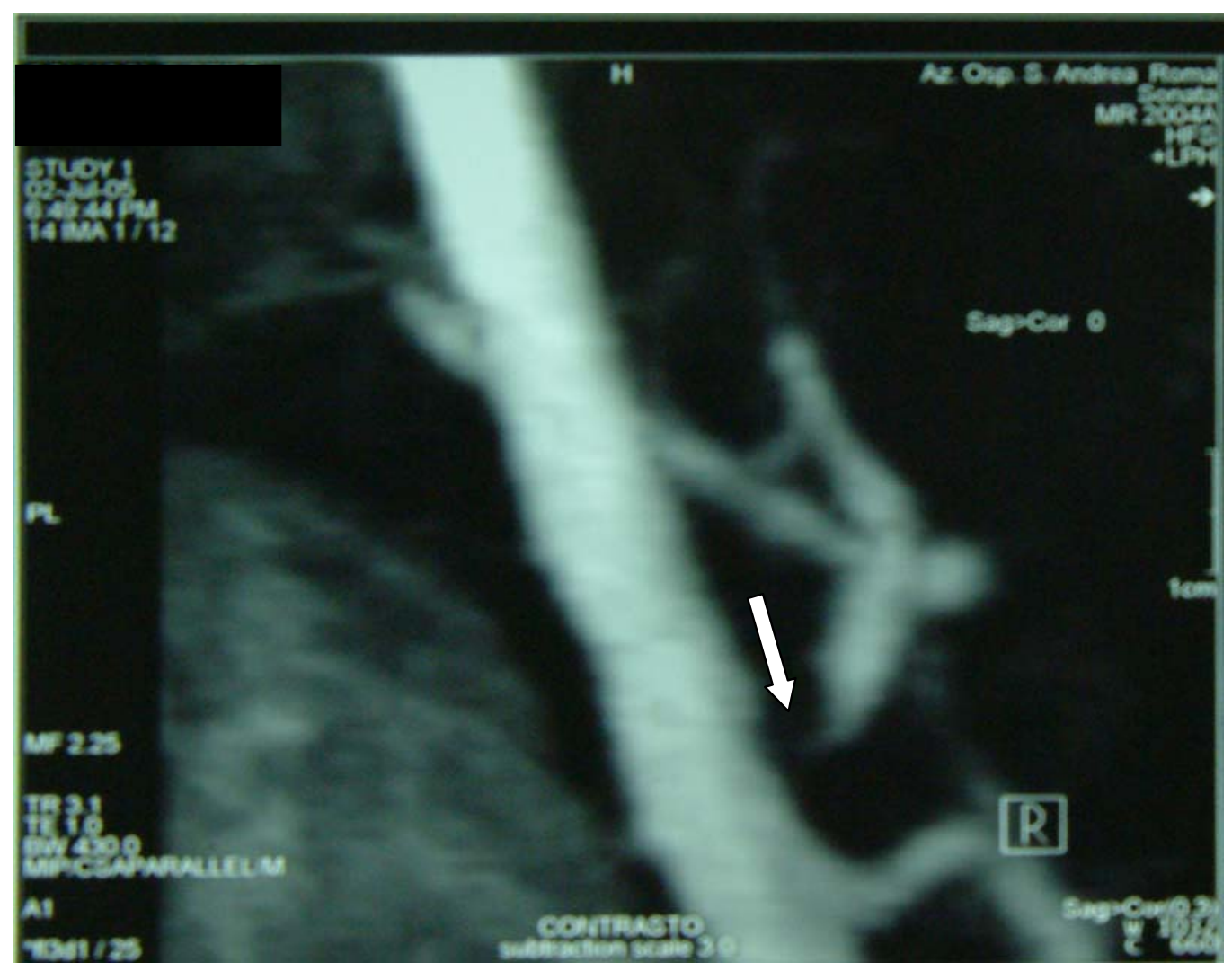

Fig. (1). Stenosis of the celiac artery resulting from median arcuate ligament narrowing (arrow). 
compression of the celiac artery by the median arcuate ligament of the diaphragm causes intestinal or diaphragmatic ischaemia, which produces symptoms $[1,7,9]$.

The vascular etiology of symptoms however is still uncertain and controversial.

Others investigators have proposed that these signs and symptoms have a neurogenic origin [26] depending from a compression of the celiac ganglion or a fibrous celiac plexus overlying the celiac trunk which determine an altered gastric electrical rhythm [25].

Questions have emerged also as to whether celiac artery compression syndrome exists from the frequent observation of celiac compression in asymptomatic patients $[2,16,22]$ but it might be due to the presence of an extensive well developed collateral pathways between the celiac artery and the mesenteric circulation [27].

Our case seems to confirm the vascular ischemic etiology of the symptomatology related to Dunbar's syndrome. Abdominal pain emerging 30 minutes after forced ice water ingestion may be interpreted due to decreased gastrointestinal blood flow and increasing metabolic requests correlated to mucosal cold water contact and successive discrepancy ischemia related to gastric parietal vessels vasodilatation.

Despite these controversies, there is a general agreement that patients with celiac axis compression which are symptomatic may benefit from proper open or minimally invasive laparoscopic surgical treatment [3,5,7,28].

It remains to individuate and recognize these patients for a correct differential diagnosis of epigastric pain even in the ED in order to choose the optimal treatment.

\section{CONFLICT OF INTEREST}

None of the authors have any financial or personal relationship with other people, or organizations, that could inappropriately influence this work.

\section{REFERENCES}

[1] Desmond CP, Roberts SK. Exercise related abdominal pain as a manifestation of the median arcuate ligament syndrome. Scand $\mathbf{J}$ Gastroenterol 2004; 39(12): 1310-13.

[2] Alehan D, Dogan OF. Pediatric surgical image. A rare case: celiac artery compression syndrome in an asymptomatic child. J Pediatr Surg 2004; 39(4): 645-7.

[3] Carbonell AM, Kercher KW, Heniford BT, Matthews BD. Laparoscopic management of median arcuate ligament syndrome. Surg Endose 2005; 19: 729.

[4] Linares P, Vivas S, Dominguez A, et al. An uncommon association of abdominal vascular compression syndromes: Dumbar and Nutcracher. Eur J Gastroenterol Hepatol 2002; 14: 1151-3.

[5] Roayaie S, Jossart G, Gitlitz D, et al. Laparoscopic release of celiac artery compression syndrome facilitated by laparoscopic ultrasound scanning to confirm restoration of flow. J Vasc Surg 2000; 32: 8147.

[6] Kalra M, Panneton JM, Hofer JM, Andrews JC. Aneurysm and stenosis of celiomesenteric trunk : a rare anomaly. J Vasc Surg 2003; 37: 679-82

[7] Kokotsakis JN, Lambidis CD, Lioulias AG, et al. Celiac artery compression syndrome. Cardiovasc Surg 2000; 8(3): 219-22.

[8] Wolfman D, Bluth EI, Sossaman J. Median arcuate ligament syndrome. J Ultrasound Med 2003; 22: 1377-80 .

[9] Kophecky K, Stine S, Dalsing M, Gottlieb K. Median arcuate ligament syndrome with multivessel involvment: diagnosis with spiral CT angiography. Abdom Imaging 1997; 22: 318-20.

[10] Gray H, Williams PL, Bannitzer LH. Gray's Anatomy 38th ed. New York, NY: Churchill Livingstone; 1995.

[11] Lindner HH, Komprud E. A clinical anatomic study study of the arcuate ligament of the diaphragm. Arch Surg 1971; 103: 600-5.

[12] Snyder MA, Mahoney EB, Rob CG. Symptomatic celiac artery stenosis due to constriction by the neurofibrous tissue of the celiac ganglion. Surgery 1967; 61:372-6.

[13] Lipshutz B. A composite study of the celiac axis stenosis. Ann Surg 1917; 65: 159-69.

[14] Harjola PT. A rare obstruction of the celiac artery : report of a case. Ann Chir Gynaecol Fenn 1963; 52: 547-50.

[15] Dunbar JD, Molnar W, Beman FF, Marable SA. Compression of the celiac artery trunk and abdominal angina. Am J Roentgenol Radium Ther Nucl Med 1965; 95: 731-44.

[16] Szilagyl DE, Rian RI, Elliott JP, Smith RF. The celiac artery compression syndrome: does it exist ? Surgery 1972; 72: 849-63 .

[17] Bron KM, Redman HC. Splancnic artery stenosis and occlusion : incidence, artheriographic and clinical manifestations. Radiology 1969; 92: 323-8.

[18] Bech F, Loesberg A, Rosenblum J, Glagov S, Gewertz BL. Median arcuate ligament compression syndrome in monozygotic twins. J Vasc Surg 1994; 19: 934-8.

[19] Reuter SR. Accentuation of celiac compression by the median arcuate ligament of the diaphragm during deep expiration. Radiology 1971; 98: 561-4.

[20] Reuter SR, Bernstein EF. The anatomic basis for respiratory variation in median arcuate ligament compression of the celiac artery. Surgery $1973 ; 73: 381-5$.

[21] Patten RM, Coldwell DM, Ben-Menachem Y. Ligamentous compression of the celiac axis. CT findings in five patients. Am J Roentgenol 1991; 156(5): 1101-3.

[22] Lee VS, Morgan JN, Tan AGS, et al. Celiac artery compression by the median arcuate ligament : a pitfall of end expiratory MR imaging. Radiology 2003; 228: 437-42.

[23] Habre J, Bernard L, Bereder M, et al. Rupture of a pancreaticoduodenal artery aneurism with median arcuate ligament syndrome: report of a case. Ann Chir 2005; 130(3): 178-80.

[24] Arcari L. Mitral valve prolapse associated with celiac artery stenosis : a new ultrasonographic syndrome? Cardiovasc Ultrasound 2004; 2: 28-37.

[25] Babalan DH, Chen J, Lin Z, Tribble CG, Mc Callum RW. Median arcuate ligament syndrome : a possible cause of idiopathic gastroparesis. Am J Gastroenterol 1997; 92: 519-23.

[26] Marable SA, Molnar W, Berman FM. Abdominal pain secondary to celiac axis compression. Am J Surg 1966; 111: 493-5.

[27] Fujisava Y, Morishita K, Fukada J, et al. Celiac artery compression sindrome due to acute type B aortic dissection. Ann Vasc Surg 2005: 27 [Epub ahead of print].

[28] Dordoni L, Tshomba Y, Giacomelli M, Jannaello AM, Chiesa R. Celiac artery compression syndrome: successful laparoscopic treatment - a case report. Vasc Endovasc Surg 2002; 36(4): 317-21. 